\title{
BMJ Open Corticosteroids and risk of gastrointestinal bleeding: a systematic review and meta-analysis
}

\author{
Sigrid Narum, ${ }^{1,2}$ Tone Westergren, ${ }^{3}$ Marianne Klemp ${ }^{4,5}$
}

To cite: Narum S, Westergren T, Klemp M. Corticosteroids and risk of gastrointestinal bleeding: a systematic review and meta-analysis. BMJ Open 2014:4:e004587.

doi:10.1136/bmjopen-2013004587

- Prepublication history and additional material is available. To view please visit the journal (http://dx.doi.org/ 10.1136/bmjopen-2013004587)

Received 30 November 2013 Revised 23 April 2014 Accepted 25 April 2014

CrossMark

For numbered affiliations see end of article.

Correspondence to

Sigrid Narum;

sigrid.narum@diakonsyk.no
ABSTRACT

Objective: To assess whether corticosteroids are associated with increased risk of gastrointestinal bleeding or perforation.

Design: Systematic review and meta-analysis of randomised, double-blind, controlled trials comparing a corticosteroid to placebo for any medical condition or in healthy participants. Studies with steroids given either locally, as a single dose, or in crossover studies were excluded.

Data sources: Literature search using MEDLINE, EMBASE and Cochrane Database of Systematic Reviews between 1983 and 22 May 2013.

Outcome measure: Outcome measures were the occurrence of gastrointestinal bleeding or perforation. Predefined subgroup analyses were carried out for disease severity, use of non-steroidal anti-inflammatory drugs (NSAIDs) or gastroprotective drugs, and history of peptic ulcer.

Results: 159 studies ( $N=33$ 253) were included. In total, $804(2.4 \%)$ patients had a gastrointestinal bleeding or perforation $(2.9 \%$ and $2.0 \%$ for corticosteroids and placebo). Corticosteroids increased the risk of gastrointestinal bleeding or perforation by $40 \%$ (OR $1.43,95 \% \mathrm{Cl} 1.22$ to 1.66). The risk was increased for hospitalised patients (OR $1.42,95 \% \mathrm{Cl}$ 1.22 to 1.66). For patients in ambulatory care, the increased risk was not statistically significant (OR 1.63, $95 \% \mathrm{Cl} 0.42$ to 6.34 ). Only 11 gastrointestinal bleeds or perforations occurred among 8651 patients in ambulatory care $(0.13 \%)$. Increased risk was still present in subgroup analyses (studies with NSAID use excluded; OR $1.44,95 \% \mathrm{Cl} 1.20$ to 1.71 , peptic ulcer as an exclusion criterion excluded; OR $1.47,95 \% \mathrm{Cl}$ 1.21 to 1.78 , and use of gastroprotective drugs excluded; OR 1.42, 95\% Cl 1.21 to 1.67 ).

Conclusions: Corticosteroid use was associated with increased risk of gastrointestinal bleeding and perforation. The increased risk was statistically significant for hospitalised patients only. For patients in ambulatory care, the total occurrence of bleeding or perforation was very low, and the increased risk was not statistically significant.

\section{INTRODUCTION}

The association between corticosteroid use and gastrointestinal (GI) adverse effects, including bleeding or perforation, has been

\section{Strengths and limitations of this study}

- This systematic review and meta-analysis includes published results from 159 trials with a total of 33253 participants.

- The strength of this systematic review is the size due to the inclusion of a large number of randomised controlled trials that allowed for subgroup analyses.

- Limitations are the possible loss of relevant studies due to the selected search strategy, the quality of adverse event reporting in the primary studies and the heterogeneity in the patient populations.

a source of debate since the $1950 \mathrm{~s}^{1-3}$ Since GI bleeding and perforation are rare events, no single randomised controlled trial has been large enough to show any increased risk for GI bleeding with the use of corticosteroids. Adverse effects and studies of rare events can often be effectively investigated in observational studies. Thus controlled, observational studies may be the method of choice to detect rare adverse effects. For corticosteroid use, several observational studies have been performed to clarify whether corticosteroids do induce GI bleeding or not, but there is still uncertainty whether this adverse effect is a result of corticosteroid use, use of other medications, underlying disease or other causes. ${ }^{4-7}$

This lack of evidence is reflected in the literature. In databases and in product monographs for corticosteroids, peptic ulcer disease and GI bleeding may or may not be described as possible adverse effects. ${ }^{8-13}$ Similarly, in clinical recommendations, an association between corticosteroid use and peptic ulcer has been described as unlikely, and the value of antiulcer prophylaxis has been questioned due to a low bleeding risk. ${ }^{8-13}$ Although many gastroenterologists consider corticosteroids as not having ulcerogenic properties, a recent survey has shown that corticosteroids are still considered 
ulcerogenic by a majority of physicians and that a majority of practitioners would treat corticosteroid users with ulcer prophylaxis. ${ }^{14}$ This uncertainty may have consequences for clinical recommendations and treatment guidelines, and is the main reason why we performed this systematic review. ${ }^{15-18}$

GI bleeding, bleeding peptic ulcer and perforation are feared complications of peptic ulcer disease, associated with considerable morbidity and mortality. ${ }^{19} 20$ Non-steroidal anti-inflammatory drugs (NSAID) use and Helicobacter pylori infection are the most important risk factors for peptic ulcer disease. Bleeding or perforation is also seen as complications to stress ulcers among patients with critical illness in intensive care units. GI bleeding and perforation are assumed to occur when ulcers erode into underlying vessels. The mechanism by which corticosteroids might induce GI bleeding or perforation has not been fully established, but corticosteroids may impair tissue repair, thus leading to delayed wound healing. ${ }^{8}$ In addition, the anti-inflammatory and analgesic properties of corticosteroids may mask symptoms of gastroduodenal ulcers and ulcer complications and thus possibly delay diagnosis.

The aim of this systematic review was to examine whether use of systemic corticosteroids was associated with an increased risk of peptic ulcer complications such as GI bleeding or perforation. Since observational studies have not been conclusive, we have chosen to include published studies with a randomised, controlled design.

\section{METHODS}

\section{Search strategy and selection criteria}

A systematic literature search was performed to identify randomised, double-blind, placebo controlled trials in which any systemic corticosteroid (defined as oral, intravenous or intramuscular) or a placebo had been administrated to randomly selected groups of patients in the treatment of a medical disorder or to healthy participants.

We searched the databases MEDLINE and EMBASE with no language restrictions between 1983 (since date of the latest review by Conn and Poynard $)^{1}$ and 30 June 2011 using the following text words: ( $\beta$ methasone/ or dexamethasone/ or methylprednisolone/ or prednisolone/ or prednisone/ or triamcinolone/ or cortisone/ or hydrocortisone/). The search was limited to randomised controlled trials, humans, double blind.mp and placebo.mp. An updated search was performed on 22 May 2013. For the full search strategy, see online supplementary file 1. An additional search was performed in the Cochrane Database of Systematic Reviews for corticosteroids and the following text words: traumatic injury, sepsis/septic shock, meningitis, bronchopulmonary dysplasia, liver diseases, lung diseases and rheumatoid arthritis. Only results fully reported in journal articles in English, German or any Scandinavian language were considered for inclusion. Whenever a title or abstract suggested that a randomised, double-blind, placebo controlled trial comparing a corticosteroid to placebo had been performed, the full text version was reviewed for documentation of GI adverse events. Articles with documentation of GI adverse effects or with assessment of adverse event monitoring described in the methods section were included. Titles, abstracts and full-text articles were evaluated and reviewed for inclusion by at least two of the authors. Disagreements were resolved by consensus among the authors.

Methodological quality assessment of eligible trials was carried out by including only randomised, double-blind studies. ${ }^{21}$ In most studies, there was no specific description of randomisation and allocation concealment, blinding methods or handling of withdrawals. Authors' description of randomisation and double blinding was assumed to be valid. We used intention-to-treat data when available. All types of comedications were allowed if administered systematically to both groups or as a part of standard care. No medical disorder or age groups were excluded. When medications known to induce GI symptoms, such as NSAIDs or acetylsalicylic acid (ASA), had been used, they were analysed as covariables. We excluded trials with a crossover design because of potential difficulties in assessment between the treatment groups. Trials in which the steroid was given as a single dose were also excluded due to the generally short follow-up.

\section{Data extraction and outcomes reporting}

For the diagnosis of complications of gastroduodenal ulcers, such as occult or visible blood in stool, GI bleeding, haematemesis, melena and GI perforation, the investigators' diagnoses were accepted as valid without requiring specific criteria or methods. Outcomes like dyspepsia, gastritis, duodenitis and epigastric pain were not included, and nor was necrotising enterocolitis. For assessment of GI bleeding or perforation as an adverse effect, the number of events should be reported in the results section as text or in a table. Events reported as percentages only were calculated into numbers by us. In some trials, other adverse effects were reported in the results section but no GI bleeding was listed. These studies were included only if adverse event monitoring was described in the methods section or if it was judged reasonable to expect from the adverse event monitoring system that any GI adverse effects would have been recorded.

We recorded information on study characteristics and demographics such as publication year, corticosteroid use, indication for treatment, use of concomitant medications, description of adverse effects, study size, duration of treatment and follow-up. Severity of disease was assessed by assuming that patients needing hospitalisation were sicker than patients in ambulatory care. Information regarding exclusion from study by ongoing, recent or a history of peptic ulcer disease was also recorded. Risk of bias was assessed by recording which methods were used for monitoring, definition and description of adverse effects, randomisation and selection criteria. 


\section{Statistical analysis}

The relative frequencies of the adverse effects were compared in the placebo and the corticosteroid group(s) using conventional statistics and meta-analysis. Subgroup analyses were performed for different predefined variables, such as for concomitant NSAID use, for use of gastroprotective drugs (proton pump inhibitors, H2 blockers or antacids) and for disease severity.

All meta-analytic calculations were made with RevMan (V.5.2) using the Mantel-Haenszel method with the random effects model. For other statistics, SPSS (V.20) was used. For binary outcomes, we calculated ORs and 95\% CIs. All analyses were two tailed, with an $\alpha$ of 0.05 .

\section{RESULTS}

\section{Literature search and study selection}

The search process identified 3483 records from database searches and 15 studies were retrieved by hand searching. A total of 159 articles fitted our inclusion criteria and were included in the review. Further details regarding study inclusion and exclusion are shown in figure 1. We performed an updated search on 22 May 2013 and retrieved three additional studies reporting confirmed GI bleeding events. The new studies did not change the results.

\section{Characteristics of included studies}

In this systematic review, 159 studies were included. The main medical conditions were severe infections, lung diseases, traumatic injuries and prevention of bronchopulmonary dysplasia in premature infants.
Further details regarding the disease groups are shown in table 1.

The corticosteroids used were dexamethasone (55), prednisolone (30), methylprednisolone (29), prednisone (22), hydrocortisone (16) and other steroids or combinations (7). The sample size ranged from 15 to 10008 people, with a median sample size of 86 . The median duration of treatment was 8.5 days (range 11095 days), and the median follow-up period was 56 days (range 1-1155 days). There was a trend towards shorter duration of treatment and follow-up during hospital treatment (6 and 33 days) compared with ambulant treatment ( 14 and 58 days; $\mathrm{p}=0.061$ and 0.057 , respectively). The adverse effects were described as any form of bleeding in 59 studies (upper/lower, minor, haematemesis, melena, visible/occult blood in stool), perforation in seven studies (perforated gastric ulcer, ileum perforation) and bleeding and perforation in six studies. The definition of GI bleeding varied between the studies, from bleeding requiring transfusion to occult blood in stool.

Altogether, 72 (45.3\%) studies reported GI bleeding or perforation as an adverse effect (67 hospitalised, 5 ambulant). In the 87 studies without reporting of any GI bleeding or perforation, peptic ulcer was described in only four studies.

Use of concomitant medication was described in 135 studies $(84.9 \%)$. In addition, use of concomitant medication was likely in many of the remaining 24 studies, as a consequence of diagnoses such as acute respiratory distress syndrome, bronchopulmonary dysplasia and traumatic injury to the head or spine. Use of medication

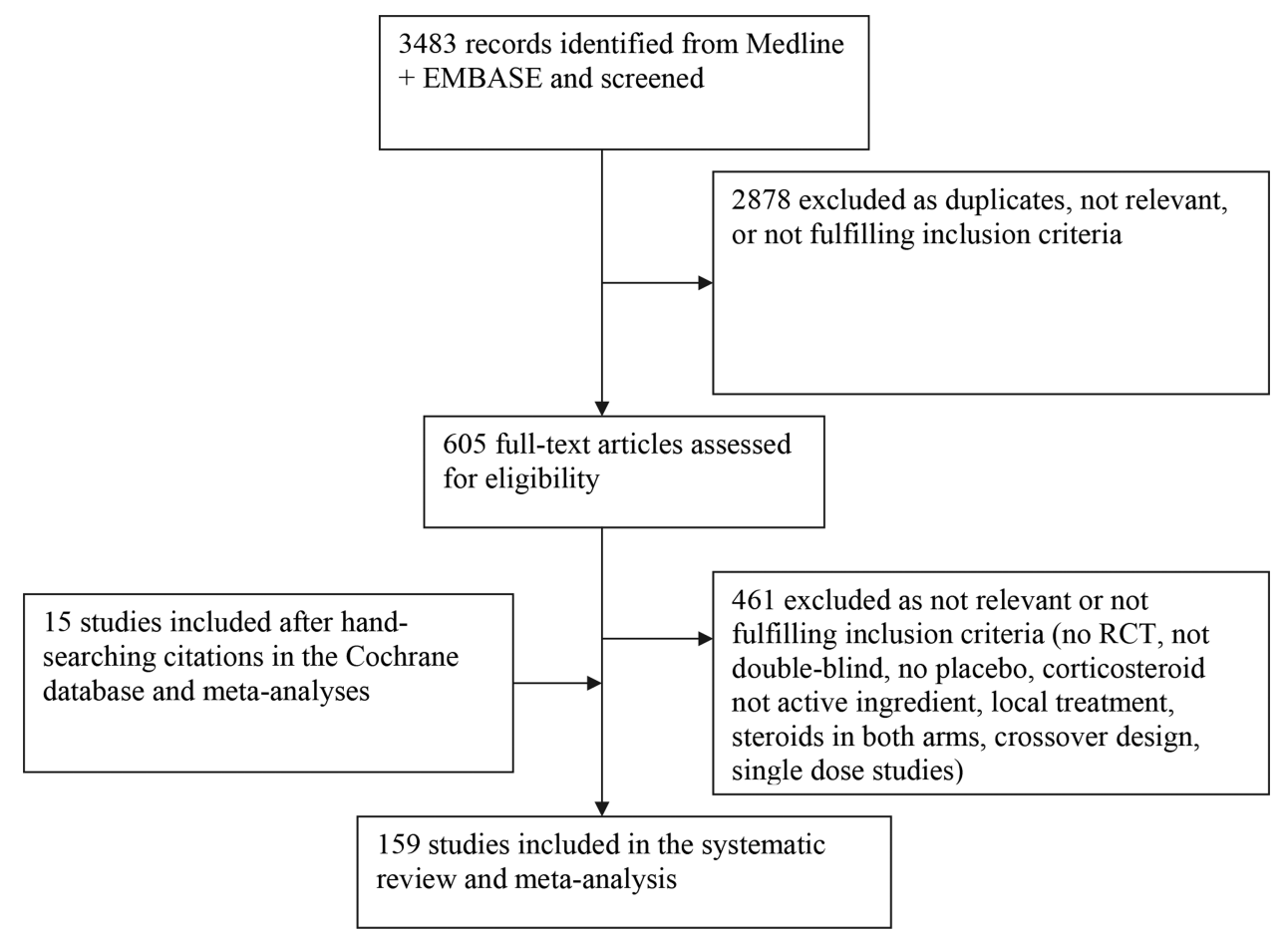

Figure 1 Flowchart for the selection of eligible studies. 
Table 1 Medical conditions in which corticosteroids were tested, with number of studies, number of participants and number of adverse effects

\begin{tabular}{|c|c|c|c|c|c|c|c|c|c|c|c|}
\hline \multirow[b]{3}{*}{ Disease } & \multicolumn{5}{|c|}{ Hospitalised } & \multicolumn{5}{|l|}{ Ambulant } & \multirow{3}{*}{$\begin{array}{l}\text { Total } \\
\text { Number of } \\
\text { participants } \\
\text { Sum }\end{array}$} \\
\hline & \multirow{2}{*}{$\begin{array}{l}\text { Number } \\
\text { of studies }\end{array}$} & \multicolumn{2}{|c|}{$\begin{array}{l}\text { Number of } \\
\text { participants }\end{array}$} & \multicolumn{2}{|c|}{$\begin{array}{l}\text { Number of } \\
\text { adverse } \\
\text { effects }\end{array}$} & \multirow{2}{*}{$\begin{array}{l}\text { Number of } \\
\text { studies }\end{array}$} & \multicolumn{2}{|c|}{$\begin{array}{l}\text { Number of } \\
\text { participants }\end{array}$} & \multicolumn{2}{|c|}{$\begin{array}{l}\text { Number of } \\
\text { adverse } \\
\text { effects }\end{array}$} & \\
\hline & & Ster & Plac & $\overline{\text { Ster }}$ & Plac & & Ster & Plac & $\overline{\text { Ster }}$ & Plac & \\
\hline $\begin{array}{l}\text { Traumatic injury } \\
\text { (brain, spinal cord, multiple) }\end{array}$ & 9 & 5821 & 5790 & 95 & 75 & 0 & - & - & - & - & 11611 \\
\hline Meningitis & 18 & 1589 & 1549 & 110 & 91 & 0 & - & - & - & - & 3138 \\
\hline Sepsis/septic shock & 7 & 482 & 449 & 32 & 28 & 0 & - & - & - & - & 931 \\
\hline Bronchopulmonary dysplasia & 21 & 1508 & 1487 & 155 & 85 & 0 & - & - & - & - & 2995 \\
\hline Liver diseases* & 4 & 150 & 114 & 26 & 15 & 3 & 705 & 709 & 5 & 1 & 1678 \\
\hline Lung diseases \% & 20 & 1149 & 1105 & 8 & 3 & 7 & 537 & 544 & 0 & 0 & 3335 \\
\hline Rheumatoid arthritis & 0 & - & - & - & - & 5 & 283 & 279 & 1 & 2 & 562 \\
\hline Miscellaneous $†$ & 24 & 1743 & 1666 & 46 & 24 & 41 & 2806 & 2788 & 2 & 0 & 9003 \\
\hline Sum & 103 & 12442 & 12160 & 472 & 321 & 56 & 4331 & 4320 & 8 & 3 & 33253 \\
\hline
\end{tabular}

Grouping by treatment level was based on statements in the reports and, if there was no indication of treatment level, on clinical judgement. Patients with traumatic injury, meningitis, sepsis/septic shock and bronchopulmonary dysplasia wer defing as hospitalised.

sepsis/septic shock and bronchopulmonary dysplasia were defined as hospitalised.

*Hepatitis, liver cirrhosis, acute hepatic failure. \% Asthma, ARDS, bronchiolitis, chronic obstructive pulmonary disease, pneumonia, tuberculosis, ventilator weaning.

†Miscellaneous diseases as stated in the original reports (number of studies in brackets): acute otitis media, adhesive capsulitis, allergic rhinitis, Alzheimer's disease, Behçet's syndrome, Bell's palsy (2), carpal tunnel syndrome, cerebral infarction, chronic fatigue syndrome, coronary artery bypass grafting (2), cysticercus granuloma with seizures, depression, Duchenne's muscular

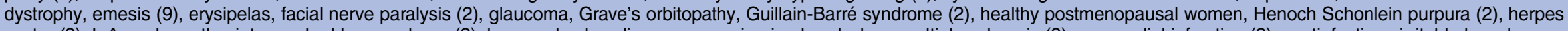
zoster (3), IgA nephropathy, intracerebral haemorrhage (2), leprosy, lumbar disc surgery, migraine headaches, multiple sclerosis (3), myocardial infarction (2), postinfectious irritable bowel syndrome, preeclampsia, (pre)terminal cancer (2), aphthous stomatitis, sinonasal polyposis, sinusitis, Sjøgren's syndrome, Sydenham's Chorea in children, tetanus, tonsillectomy (2), tuberculous pericarditis in HIV, typhoid fever, urticaria, vestibular neuritis, withdrawal headache.

ARDS, acute respiratory distress syndrome; Plac, placebo; Ster, corticosteroids. 
for any pre-existing diseases was sparsely described. Concomitant use of NSAIDs/ASA was described in 19 studies (bronchopulmonary dysplasia, rheumatoid arthritis, miscellaneous and sepsis in 9 studies, 5 studies, 4 studies and 1 study, respectively), and use of gastroprotective drugs was described in 14 studies. In addition, use of concomitant drugs 'according to standard clinical practice', etc, which may potentially include use of gastroprotective drugs, was described in 12 studies.

Peptic ulcer, ongoing, recent or previous, was an exclusion criterion in $53(33.3 \%)$ of the studies. In the majority of studies $(85,53.5 \%)$, the authors reported no effect of corticosteroids on the primary efficacy endpoint. Study-specific characteristics are shown in table 2 and in online supplementary file 2 .

\section{Risk of Gl bleeding or perforation}

The analysis included 33253 participants (16 773 received corticosteroids and 16480 received placebo). Of those, 804 patients (480 receiving a corticosteroid and 324 receiving a placebo) were reported to have a GI bleeding or perforation, which comprises $2.4 \%$ of the study participants $(2.9 \%$ and $2 \%$ for corticosteroids and placebo, respectively). Overall, meta-analysis of all the included studies showed a $40 \%$ increased OR of experiencing GI bleeding or perforation among corticosteroid users compared with placebo users (OR 1.43, 95\% CI 1.22 to 1.66 ; figure 2 , and see online supplementary file 3). Subgroup analysis for each disease group showed a trend towards an increased risk of GI bleeding or perforation in seven out of eight subgroups, but the result was statistically significant only for premature infants in prevention of bronchopulmonary dysplasia $(1.83,1.37$ to 2.43).

\section{Sensitivity analyses}

Data from subgroup analyses are shown in table 3 .

Subgroup analysis of studies with hospitalised patients showed an increased risk of developing GI bleeding or perforation (OR 1.42, 95\% CI 1.22 to 1.66). There was also a trend towards increased risk for patients in ambulatory care $(1.63,0.42$ to 6.34$)$, but this result was not significant. When the studies with documentation of concomitant NSAID use were excluded, a significant difference between corticosteroid and placebo with respect to GI bleeding or perforation was still present (1.44, 1.20 to 1.71 ). When all studies of premature infants in prevention of bronchopulmonary dysplasia were excluded from the analysis (assuming NSAIDs were given in all studies), the results were lower but still significant $(1.29,1.07$ to 1.55$)$. When studies with peptic ulcer as an exclusion criterion and studies with concomitant use of gastroprotective drugs were subsequently excluded from the analyses, there was little change in the risk of bleeding or perforation in the remaining studies (table 3). The majority of the adverse effects occurred in hospitalised patients. Only 11 GI bleedings or perforations occurred among 8651 patients in

\begin{tabular}{|c|c|c|c|c|}
\hline Summary of study characteristics & Studies total & Studies with bleeding & Studies without bleeding & p Values \\
\hline Studies included (\%) & 159 & $72(45.3)$ & $87(54.7)$ & \\
\hline Year of publication, median & & 1998 & 1999 & 0.109 \\
\hline \multicolumn{5}{|l|}{ Description of adverse effect (\%) } \\
\hline Bleeding & & $59(81.9)$ & 0 & \\
\hline Perforation & & $7(9.7)$ & 0 & \\
\hline Bleeding and perforation & & $6(8.3)$ & 0 & \\
\hline Peptic ulcer only & & & 4 & \\
\hline \multicolumn{5}{|l|}{ Level of care (\%) } \\
\hline Hospitalised & 103 & $67(93.1)$ & $36(41.4)$ & $<0.001$ \\
\hline Ambulant & 56 & $5(6.9)$ & $51(58.6)$ & \\
\hline \multicolumn{5}{|l|}{ Use of concomitant medication (\%) } \\
\hline No concomitant medication described & 24 & $11(15.3)$ & $13(14.9)$ & \\
\hline Concomitant medication described & 135 & $61(84.7)$ & $74(85.1)$ & \\
\hline NSAIDs/ASA & 19 & $11(15.3)$ & $8(9.2)$ & 0.326 \\
\hline Gastroprotective drugs & 14 & 12 & 2 & 0.002 \\
\hline \multicolumn{5}{|l|}{ Exclusion criteria (\%) } \\
\hline Recent/ongoing peptic ulcer & 36 & $14(19.4)$ & $22(25.3)$ & 0.237 \\
\hline Previous/history of peptic ulcer & 17 & $6(8.3)$ & $11(12.6)$ & \\
\hline \multicolumn{5}{|l|}{ Study size, number of participants } \\
\hline Median (IQR) & $86(49.0-181.0)$ & $100(60.3-246.5)$ & $70(40.0-128.0)$ & 0.104 \\
\hline \multicolumn{5}{|l|}{ Duration of treatment, days } \\
\hline Median (IQR) & $8.5(3.3-28.0)$ & $6.0(3.0-12.0)$ & $14(4.0-45.0)$ & 0.061 \\
\hline \multicolumn{5}{|l|}{ Duration of follow-up, days } \\
\hline Median (IQR) & $56(21.0-243.8)$ & $33(21.0-180.0)$ & $58(19.5-286.5)$ & 0.057 \\
\hline
\end{tabular}




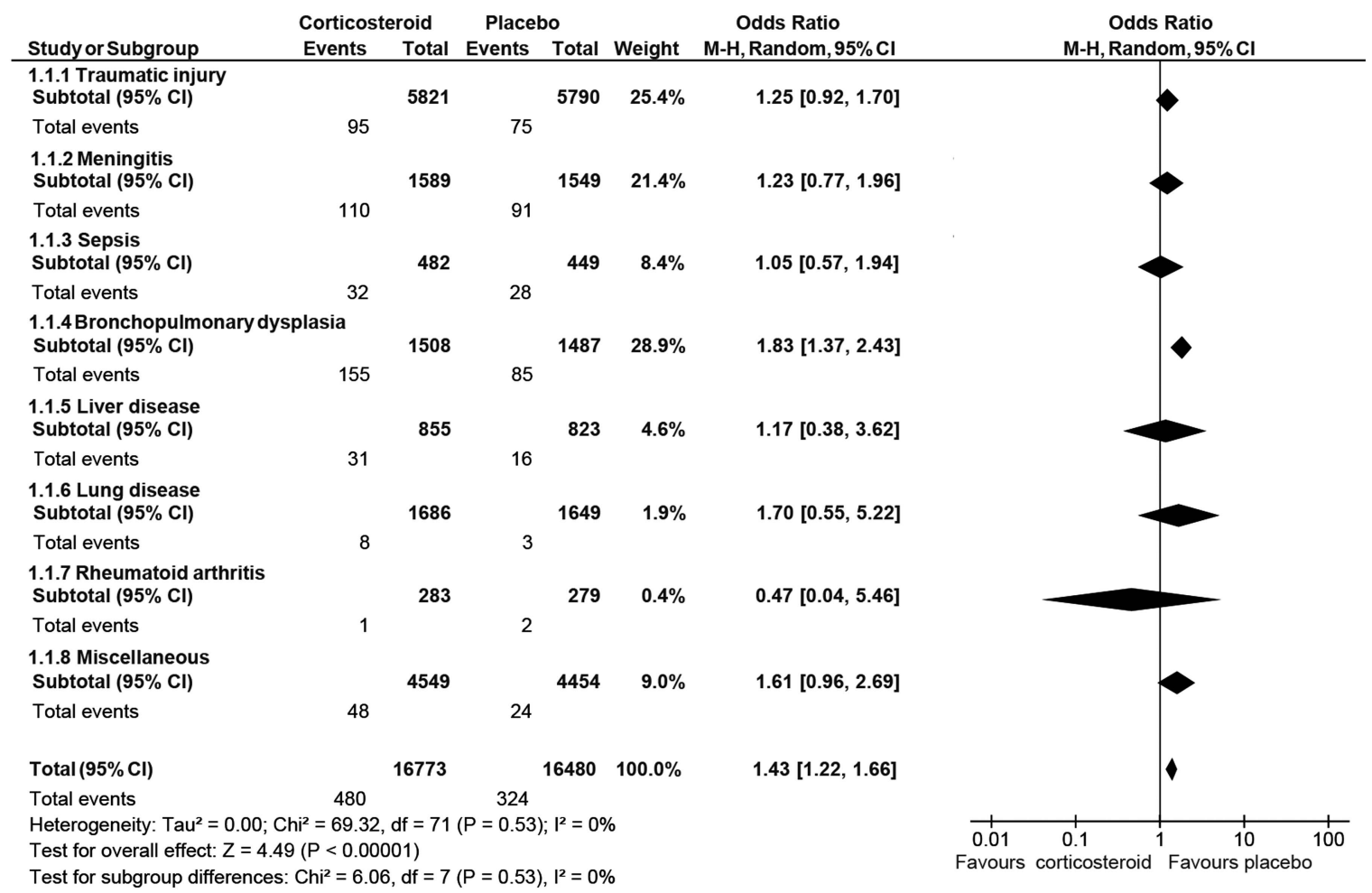

Figure 2 Summary of pooled results. Gastrointestinal bleeding in corticosteroid users versus placebo users. The Mantel-Haenszel $(\mathrm{M}-\mathrm{H})$ method with a random effects model was used.

ambulatory care $(0.13 \%)$, compared with 793 GI bleeds or perforations among 24602 hospitalised patients $(3.22 \%$; $\mathrm{p}<0.001$; table 1$)$. The absolute risk of experiencing GI bleeding, events per 1000 patients, was 1.8 for ambulant patients given steroids, compared with 0.7 for ambulant patients given placebo (table 3). In contrast, hospitalised patients had a much higher risk, 37.9/1000 for steroids and 26.4/1000 for placebo.

\section{DISCUSSION}

The overall findings of this systematic review show that the use of corticosteroids may increase the OR by $40 \%$ for GI bleeding or perforation. The increased risk, however, was limited to hospitalised patients. For patients in ambulatory care, who had a very low absolute occurrence of GI bleeding or perforation, the increased risk was not statistically significant. The results persisted when high-risk/low-risk patients (concomitant NSAID use, previous peptic ulcer as an exclusion criterion and use of gastroprotective drugs) were excluded, indicating the robustness of the results.

\section{Comparison with other studies}

Previously published meta-analyses addressing whether corticosteroid use predisposes people to GI bleeding or perforation have shown conflicting results. ${ }^{1-3}$ In two

Table 3 Summary of subgroup analyses

\begin{tabular}{|c|c|c|c|c|c|}
\hline & $\begin{array}{l}\text { Number } \\
\text { of studies }\end{array}$ & $\begin{array}{l}\text { Number } \\
\text { of patients }\end{array}$ & OR $(95 \% \mathrm{Cl})$ & $\begin{array}{l}\text { Events } \\
\text { steroids/ } \\
\text { placebo }\end{array}$ & $\begin{array}{l}\text { Events per } 1000 \\
\text { patients steroids/ } \\
\text { placebo }\end{array}$ \\
\hline Hospitalised & 103 & 24602 & $1.42(1.22$ to 1.66$)$ & $472 / 321$ & $37.9 / 26.4$ \\
\hline Ambulant & 56 & 8651 & $1.63(0.42$ to 6.34$)$ & $8 / 3$ & $1.8 / 0.7$ \\
\hline NSAID use not documented & 140 & 30874 & $1.44(1.20$ to 1.71$)$ & $372 / 248$ & 23.9/16.2 \\
\hline NSAID use documented & 19 & 2379 & 1.30 (0.81 to 2.07$)$ & $108 / 76$ & $90.2 / 64.4$ \\
\hline $\begin{array}{l}\text { Peptic ulcer as an exclusion criterion not } \\
\text { documented }\end{array}$ & 106 & 25760 & $1.47(1.21$ to 1.78$)$ & $421 / 284$ & $32.5 / 22.1$ \\
\hline $\begin{array}{l}\text { Peptic ulcer as an exclusion criterion } \\
\text { documented }\end{array}$ & 53 & 7493 & $1.26(0.81$ to 1.96$)$ & $59 / 40$ & $15.4 / 10.9$ \\
\hline Gastroprotective drugs not documented & 145 & 31759 & $1.42(1.21$ to 1.67$)$ & $442 / 299$ & $27.6 / 19.0$ \\
\hline Gastroprotective drugs documented & 14 & 1494 & $1.29(0.62$ to 2.69$)$ & $38 / 25$ & $50.6 / 33.6$ \\
\hline Bronchopulmonary dysplasia excluded & 138 & 30258 & $1.29(1.07$ to 1.55$)$ & $325 / 239$ & $21.3 / 15.9$ \\
\hline
\end{tabular}


meta-analyses, Conn and colleagues ${ }^{1}{ }^{2}$ concluded that there was no increased risk of peptic ulcer, GI bleeding or perforation by corticosteroid use. In contrast, Messer et $a l^{3}$ found an increased incidence of peptic ulcer and GI bleeding. In a subgroup analysis by Conn and Blitzer, ${ }^{2}$ however, there was a significantly higher rate of GI bleeding from an unknown site among corticosteroid users compared with controls. In his second paper, steroid users had more GI adverse effects (ulcers, symptoms of ulcers, bleeding, erosions and perforation) than controls, but because of subgroup analyses only and no pooling of results, no differences emerged as statistically significant. ${ }^{1}$ These meta-analyses of randomised controlled trials, which included published literature up to 1983, show how different inclusion criteria, selection criteria, data handling and interpretation of results may give totally different results and conclusions. Newer Cochrane meta-analyses have addressed the question in selective patient populations (meningitis, traumatic brain injury and preterm infants). These analyses show a trend $^{22-24}$ or a statistically significant increase ${ }^{25}$ in the risk ratio of experiencing GI bleeding, with the included studies and results being similar to the subgroups in our study.

In our study, we included the literature published from 1983 until now. With 33253 participants from double-blind, randomised, controlled trials, this is the largest meta-analysis analysing whether corticosteroids increase the risk of GI bleeding. Owing to the large size of our study, findings that were seen as trends in other reviews or went unnoticed because of many subgroup analyses have emerged as a significant increase in risk, despite the non-significant increase in occurrence in all subgroups except prevention of bronchopulmonary dysplasia in premature infants. Surprisingly, peptic ulcers were hardly listed as an adverse effect in the included studies, in contrast to the studies in the previous reviews by Conn and Messer. One explanation may be the differences in disease panorama and the discovery and treatment of $H$. pylori. The true occurrence of peptic ulcer may also have been underestimated in the studies because of the heavy medication and intensive care treatment.

\section{Strengths and limitations of this review}

In many reviews, the use of narrow inclusion criteria and wide exclusion criteria makes the population homogeneous, but with rare events there is a high risk of insignificant results. In our analysis, inclusion of all studies with a relevant design, including those with concomitant medications and studies with zero events, may reflect more realistic treatment conditions and may contribute to the validity of the findings. Owing to the large size of included studies in our review, we were able to perform predefined subgroup analyses assessing the severity of disease (ie, assessed as hospitalised or as ambulant treatment), use of NSAIDs or gastroprotective drugs and documentation of peptic ulcer as exclusion criteria. To the best of our knowledge, this is the first systematic review to indicate that disease severity might influence the risk of GI bleeding or perforation in corticosteroid users.

The main limitations of this review are the possible loss of relevant studies due to the selected search strategy, the quality of the included trials and the heterogeneity of the included patient populations. However, we believe the findings to be robust, despite this, due to the large number of included studies and participants. Randomised controlled trials are designed to show the effect of treatment, not to detect adverse effects, which in many studies were sparsely reported or not reported at all. However, since we included only double-blind studies with placebo control, we suspect similar underreporting in both study groups. To minimise the risk of bias according to adverse effect detection and reporting, we recorded the methods used for monitoring adverse effects and how the adverse effect was defined in the primary studies. We found diversity in the definitions of GI bleeding (ie, from occult blood in stool to GI bleeding requiring transfusion or hospital stay). In addition, differences in the methods used for monitoring adverse effects may explain the risk differences found in the sensitivity analyses. A more rigorous follow-up of patients in intensive care units may thus explain some of the risk differences found between hospitalised patients and patients in ambulatory care. This makes comparisons of absolute risk differences between different disease groups difficult.

We aimed to include all disease groups, but still some groups may be under-represented (ie, rheumatoid arthritis, organ transplanted patients) since corticosteroid use is standard treatment and is no longer compared with placebo in randomised controlled trials. Patients included in randomised controlled trials may differ from patients excluded from trial participation, and may be healthier, without previous peptic ulcer. This may underestimate the true effect of corticosteroids on GI bleeding and perforation within the population. In the majority of the included studies, the use of concomitant medications was described. Concomitant medication was related to the study indication (eg, treatment of trauma, meningitis, sepsis, bronchopulmonary dysplasia, etc), in contrast to medications for coexisting diseases, which were hardly mentioned. Concomitant use of gastroprotective drugs and descriptions of supportive care according to standard clinical practice, which may include the use of gastroprotective drugs, was declared only in a minority of the studies. In addition, the potential underreporting and undisclosed use of gastroprotective drugs may have underestimated the true risk of having GI bleeding with steroid use. Undisclosed use of gastroprotective drugs may especially apply to ambulant treated patients with dyspepsia. Owing to the short-term treatment and inclusion of only double-blind studies, we assume that the effect of the possible under-reporting and undisclosed use of gastroprotective drugs was not 
substantial. Despite the heterogeneity of the included studies and a potential of under-reporting of adverse effects, there is a consistency across the analyses of an increased frequency of GI bleeding and perforation among patients given steroids compared with patients given placebo. This indicates the robustness of the analysis.

\section{Clinical implications of this review}

Our analysis shows that the increased risk of GI bleeding or perforation applied to hospitalised patients only, indicating that additional factors to corticosteroid therapy, such as disease severity or advanced medical treatment, may make some patients more vulnerable to adverse events to corticosteroid use. One possible explanation is that the bleedings and perforations seen among hospitalised patients may be complications to the stress ulcers seen in critically ill patients.

Owing to diagnoses or illnesses like traumatic injury, meningitis and sepsis, we suspected a substantial portion of the hospitalised patients to have been critically ill. To scrutinise this further, we aimed to do separate analyses of critically ill patients or treatment in intensive care units, but lack of descriptions of critical illness or treatment in intensive care units in the included studies made us use hospitalisation and ambulant treatment as surrogate markers for disease severity.

Stress ulcers occur in response to severe physiological stress in critically ill patients. Although the mechanism is not completely understood, it involves decreased mucosal blood flow and subsequent tissue ischaemia, resulting in breakdown of mucosal defences, allowing physiological factors to produce injury and ulceration. ${ }^{26}$ Many risk factors for stress ulcer bleeding have been proposed, ${ }^{26}{ }^{27}$ but only mechanical ventilation and coagulopathy have been documented as independent risk factors. Despite this evidence, several studies have shown that acid-suppressive therapy is used as stress ulcer prophylaxis in hospital wards and outpatient settings. ${ }^{15-17}$ This has been described as an inappropriate use of acidsuppressive therapy. An explanation to this overuse may be the discrepancy between product monographs and databases/clinical recommendations in assessment of peptic ulcer disease and GI bleeding as possible adverse effects to corticosteroids. ${ }^{811-13}$

Our analysis also showed increased risk of GI bleeding or perforation among patients in ambulatory care, but the result was not significant due to a very low occurrence of GI bleeding and perforation. According to our results, the data are insufficient to conclude whether corticosteroids are associated with GI bleeding or perforation among patients in ambulatory care. It seems reasonable to conclude that the absolute risk of GI bleeding is very low in the ambulatory setting.

\footnotetext{
Author affiliations

${ }^{1}$ Center for Psychopharmacology, Diakonhjemmet Hospital, Oslo, Norway

${ }^{2}$ Department of Pharmacology, Oslo University Hospital, Oslo, Norway
}

${ }^{3}$ Department of Pharmacology, Regional Medicines Information \& Pharmacovigilance Centre (RELIS), Oslo University Hospital, Oslo, Norway

${ }^{4}$ Norwegian Knowledge Centre for the Health Services, Oslo, Norway

${ }^{5}$ Department of Pharmacology, University of Oslo, Oslo, Norway

Contributors SN, TW and MK conceived the study, performed the systematic review and data extraction, analysed the data and drafted the manuscript. All authors had full access to the data and take responsibility for the integrity of the data and accuracy of the analysis. SN is the guarantor.

Funding This research received no specific grant from any funding agency in the public, commercial or not-for-profit sectors.

Competing interests None.

Provenance and peer review Not commissioned; externally peer reviewed.

Data sharing statement The dataset is available from the corresponding author.

Open Access This is an Open Access article distributed in accordance with the Creative Commons Attribution Non Commercial (CC BY-NC 3.0) license, which permits others to distribute, remix, adapt, build upon this work noncommercially, and license their derivative works on different terms, provided the original work is properly cited and the use is non-commercial. See: http:// creativecommons.org/licenses/by-nc/3.0/

\section{REFERENCES}

1. Conn HO, Poynard T. Corticosteroids and peptic ulcer: meta-analysis of adverse events during steroid therapy. J Intern Med 1994;236:619-32.

2. Conn HO, Blitzer BL. Nonassociation of adrenocorticosteroid therapy and peptic ulcer. N Engl J Med 1976;294:473-9.

3. Messer J, Reitman D, Sacks HS, et al. Association of adrenocorticosteroid therapy and peptic-ulcer disease. N Engl J Med 1983;309:21-4.

4. Nielsen GL, Sorensen HT, Mellemkjoer L, et al. Risk of hospitalization resulting from upper gastrointestinal bleeding among patients taking corticosteroids: a register-based cohort study. $A m \mathrm{~J}$ Med 2001;111:541-5.

5. Hernandez-Diaz S, Rodriguez LA. Steroids and risk of upper gastrointestinal complications. Am J Epidemiol 2001;153:1089-93.

6. Piper JM, Ray WA, Daugherty JR, et al. Corticosteroid use and peptic ulcer disease: role of nonsteroidal anti-inflammatory drugs. Ann Intern Med 1991;114:735-40.

7. de Abajo FJ, Gil MJ, Bryant V, et al. Upper gastrointestinal bleeding associated with NSAIDs, other drugs and interactions: a nested case-control study in a new general practice database. Eur J Clin Pharmacol 2013;69:691-701.

8. Corticosteroids: Introduction (Martindale: The Complete Drug Reference). 2010. [cited 2013 Feb 18]. http://online.lexi.com/lco/ action/doc/retrieve/docid/martindale_f/1353587

9. Saag KG, Furst DE. Major side effects of systemic glucocorticoids. 2012 October 11. [cited 5 Mar 2013]. http://www.uptodate.com

10. Joint Formulary Committee. British National Formulary. Side-effects of corticosteroids. 2013. [cited 14 Aug 2013]. http://www. medicinescomplete.com

11. Summary of product characteristics; Dexamethasone Tablets BP 2.0 mg. 2012 November 13. [cited 14 Aug 2013]. http://www.mhra.gov. uk/home/groups/spcpil/documents/spcpil/con1369200053458.pd

12. Summary of product characteristics; Prednisolone $5 \mathrm{mg}$ Tablets. 2011 July 5. [cited 14 Aug 2013]. http://www.mhra.gov.uk/home/ groups/spcpil/documents/spcpil/con1364186684018.pdf

13. Gold Standard, Inc. Prednisone. Clinical pharmacology 2012 September 8. [cited 11 Oct 2013 ]. http://www.clinicalpharmacology. com

14. Martinek J, Hlavova K, Zavada F, et al. "A surviving myth"corticosteroids are still considered ulcerogenic by a majority of physicians. Scand J Gastroenterol 2010;45:1156-61.

15. Heidelbaugh JJ, Inadomi JM. Magnitude and economic impact of inappropriate use of stress ulcer prophylaxis in non-ICU hospitalized patients. Am J Gastroenterol 2006;101:2200-5.

16. Zink DA, Pohlman M, Barnes M, et al. Long-term use of acid suppression started inappropriately during hospitalization. Aliment Pharmacol Ther 2005;21:1203-9.

17. Munson JC, Wahl PM, Daniel G, et al. Factors associated with the initiation of proton pump inhibitors in corticosteroid users. Pharmacoepidemiol Drug Saf 2012;21:366-74. 
18. van der Goes MC, Jacobs JW, Boers M, et al. Monitoring adverse events of low-dose glucocorticoid therapy: EULAR recommendations for clinical trials and daily practice. Ann Rheum Dis 2010;69: 1913-19.

19. Ahsberg K, Ye W, Lu Y, et al. Hospitalisation of and mortality from bleeding peptic ulcer in Sweden: a nationwide time-trend analysis. Aliment Pharmacol Ther 2011;33:578-84.

20. Lanas A, Garcia-Rodriguez LA, Polo-Tomas M, et al. The changing face of hospitalisation due to gastrointestinal bleeding and perforation. Aliment Pharmacol Ther 2011;33:585-91.

21. Juni $P$, Witschi $A$, Bloch $R$, et al. The hazards of scoring the quality of clinical trials for meta-analysis. JAMA 1999;282:1054-60.

22. Alderson $\mathrm{P}$, Roberts I. Corticosteroids for acute traumatic brain injury. Cochrane Database Syst Rev 2005;(1):CD000196.
23. Brouwer MC, McIntyre $\mathrm{P}$, de Grans J, et al. Corticosteroids for acute bacterial meningitis. Cochrane Database Syst Rev 2010;(9): CD004405.

24. Halliday HL, Ehrenkranz RA, Doyle LW. Late ( $>7$ days) postnatal corticosteroids for chronic lung disease in preterm infants. Cochrane Database Syst Rev 2009;(1):CD001145.

25. Halliday HL, Ehrenkranz RA, Doyle LW. Early ( $<8$ days) postnatal corticosteroids for preventing chronic lung disease in preterm infants. Cochrane Database Syst Rev 2010;(1):CD001146.

26. Stollman N, Metz DC. Pathophysiology and prophylaxis of stress ulcer in intensive care unit patients. J Crit Care 2005;20:35-45.

27. Cook DJ, Fuller HD, Guyatt GH, et al. Risk factors for gastrointestinal bleeding in critically ill patients. Canadian Critical Care Trials Group. N Engl J Med 1994;330:377-81. 